\title{
MONITORING MULTISPECIES INTERACTIONS: A CASE STUDY OF 16 MAIN TREE SPECIES ALONG THE NORTHEAST CHINA TRANSECT
}

\author{
X. CHEN \\ Centre for Forestry \& Ecology, Alabama A \& M University, PO Box 1927, Normal, AL 35762, \\ USA \\ (phone: 256-372-4231; fax: 256-372-8404) \\ e-mail: xiongwen.chen@email.aamu.edu \\ (Received $15^{\text {th }}$ December 2006 ; accepted $6^{\text {th }}$ July 2009)
}

\begin{abstract}
Viability of single species can be understood only in the context of ecological interactions with the other species and the environment. Monitoring multispecies interactions and their environment is critical for analysis of community dynamics, multispecies habitat conservation plans and for adaptive ecosystem management programs. In this study, three simple methods (scaling exponent of Taylor's power law, resource exploitation competition and interspecies mean crowding coefficients) based on abundance were applied to estimate multiple tree species interactions along the Northeast China Transect. This transect was identified as a middle-latitude transect for terrestrial ecosystem studies by Global Change and Terrestrial Ecosystem Program of IGBP. Our analyses show the differences and similarities of these three methods because each one emphasizes different aspects of multispecies interaction measurement. The combined use of these three methods can provide an easy and simple way to estimate multispecies interactions based on abundance of each tree species and their change under environmental change. The suggested approach could help identify indicator species for monitoring, improve population viability analysis, and set priorities species conservation.

Keywords. Interspecies mean crowding coefficients, multispecies habitat conservation plans, Northeast China Transect, resource exploitation competition, Taylor's power law
\end{abstract}

\section{Introduction}

The single species approach to monitoring is considered inefficient and ineffective $[2,5,21,23,24]$. The main issues confronting the species-by-species plan [23] are (i) entire communities rather than single species need to be the focus of conservation efforts, because species may rely on each other; (ii) information about vulnerable communities and their constituent species may be limited due to underlying complicated processes; and (iii) species always interact with each other in complicated ways. Several competitors may affect one species; the complex food webs and environmental fluctuations at a large area have different implications for different species.

Multispecies habitat conservation plans (MHCPs) have emerged and are designed to conserve the biodiversity of a region by ensuring that a representative set of species are protected and also minimize conflicts from species-by-species approaches [2, 24]. The critical requirement of these plans is monitoring site specific multispecies interactions and the interaction with the environment, which mean competition for space and resources or impact from other species and environment. Such information can also be useful for adaptive management programs. Most studies on multispecies interactions concentrate on using sophisticated models to estimate competition coefficients between species under given conditions of environmental change [10, 18]. However, building those models is difficult because it requires sufficiently detailed information and 
estimation of some parameters that are hard to measure [12, 25]. Simple and practical ways to monitor the interactions of multiple species by easily obtained and less long term time series data are much more desirable for local or regional MHCPs.

Multispecies interactions directly or indirectly impact the abundance of each species. Classical theory asserts that each species is unique in its resource demand and the resulting variation in interspecific interactions that determines biodiversity and relative abundance in a community [7]. It would be useful to be able to detect multispecies interactions from abundance of each species. These interactions could be easily monitored by data series in time or space. Currently there are three simple methods to estimate multispecies interactions by abundance. The scaling exponent of Taylor's power law was used to describe interactions from other species and environments [17]. Lloyd (1967) measured interspecies mean crowding by species abundance [20]. Measurement of mean crowding represents the extent of spatial crowding. The species resource exploitation competition coefficient was used to estimate interaction coefficient in using resources [19]. Here these three methods based on abundance analysis for monitoring changes in interactions among multiple species were compared for tree species along the Northeast China Transect (NECT). NECT was one of middlelatitude transect for terrestrial ecosystem studies by Global Change and Terrestrial Ecosystem (GCTE) of IGBP [13]. Because this transect is parallel with latitude, its vegetation change is driven mainly by moisture. The annual precipitation is as high as $800 \mathrm{~mm}$ in the east and only $100 \mathrm{~mm}$ in the west along this transect. Monitoring the change in interaction among tree species under precipitation gradients would be helpful to study these species dynamics at a large region under environmental change. Therefore, the aims of this research are to (1) compare the results of these three methods; and (2) find a simple method or synthesize a new one based on easily measured indicators (such as abundance) and less long term time series data, to detect species viability, multispecies interactions and their changes under a changing environment.

\section{Materials and methods}

\section{Study area}

Our study area was approximately from longitude $125^{\circ} \mathrm{E}$ to $130^{\circ} \mathrm{E}$ along latitude $43.55^{\circ} \mathrm{N}$. The total length was about $400 \mathrm{~km}$. The data set was selected from 100 permanent plots (each plot $30 \times 30 \mathrm{~m}^{2}$ ) sampled every $4 \mathrm{~km}$ in 1986 and 1994 . The soil type in this area is dark brown soil. Every tree with a diameter at breast height larger than $2 \mathrm{~cm}$ was recorded. Detailed information about the study area can be found in [4, $6]$.

\section{Statistical methods}

There are many studies about species interactions, however, based on simple and practical criteria, the following three methods for estimating species interactions based on abundance analysis were used in this study:

(1) Scaling exponent of Taylor's power law: Taylor's power law originally described the species-specific relationship between the temporal or spatial variance of populations and their mean abundances $[27,28]$. The negative interactions from the other species and environment in a community can produce a scaling exponent of Taylor's power law of less than 2, and that the scaling exponent decreases with increasing strength of 
interspecific competition [17]. Kendal (2002) explained Taylor's power law by an exponential dispersion model and tested it by spatial aggregation of the Colorado potato beetle [16]. In this study, the scaling exponents of the log values of mean abundance of each tree species and variance in 1986 and 1994 were estimated for the entire area and for different lengths along NECT. The results of each tree species were compared with each other and the null hypothesis of a slope of 2.0 for no interspecific interaction. Mathematically, the logistic distribution which corresponds to the logistic equation yields a scaling exponent of exactly 2. The slope may increase to 2.5 if a population is divided among heterogeneous areas with dynamically autonomous subpopulations and migration among them [1]. A reduced major axis (RMA) of regression analysis Model Type II was used to determine scaling exponents for different species in different areas. The details of statistical procedures can be found in [26].

(2) Species resource exploitation competition coefficients were estimated as the following $[8,19]$.

$$
\alpha_{i j}=\frac{\sum_{h} p_{i h} p_{j h}}{\sum_{h} p_{i h}^{2}}
$$

where $p_{i h}$ is the fraction of individuals found in location $h$ that are of species $i ; p_{j h}$ is the fraction of individuals of other species; $\alpha_{i j}$ is the interaction coefficient of species $i$ from all other species. Some workers have used the above formula or modifications thereof to measure niche overlap [11]. This formula was also used to estimate competition coefficients of ants [9]. A test of this measurement was conducted for birds in southern California and on Santa Cruz Island [29].

(3) Interspecies mean crowding was estimated by [14, 20]:

$$
m_{X Y}=\frac{\sum_{j=1}^{h} x_{X j} x_{Y j}}{\sum_{j=1}^{h} x_{X j}}
$$

where $m_{X Y}$ is the mean crowding on species $\mathrm{X}$ from species $\mathrm{Y}$, and $x_{X j}$ and $x_{Y j}$ are the abundances of species $\mathrm{X}$ and $\mathrm{Y}$ in the $j$ th quadrat, respectively. The $m_{X Y}$ was used to analyze the spatial association between two species [14]. The relationship between the mean crowding coefficient and the mean abundance was used to discuss a variety of biological distributions [15]. In this study, the mean crowding interaction on each species from all other species at different locations (with increase of distances) was estimated.

All three metrics can measure multispecies interactions, but their results may be different due to their different aims. Comparing the results of these metrics provides a potential method for monitoring multispecies interaction for the purpose of monitoring, conservation and forest management.

\section{Data compilation}

Abundance or the number of individuals of each tree species in each plot along NECT was recorded. Abundance of each species at different spatial locations along NECT was aggregated with the distance of every $50 \mathrm{~km}$ from the beginning. The fraction of individuals of species $i$ in each location or along different lengths of NECT 
was calculated as the percentage of abundance of species $i$ of the total abundance of all species. log values of mean abundance of each tree species and variance in 1986 and 1994 were calculated for the entire study area and for each $50 \mathrm{~km}$ along NECT. Then, RMA of regression analysis Model Type II was used to determine scaling exponents between $\log$ (mean abundance) and $\log$ (variance of abundance) for different species in different areas.

\section{Results}

\section{The overall interaction coefficient of each species at NECT}

The overall interaction of each species from all the others and environment can be estimated by the scaling exponent of mean abundance and variance on NECT in 1986 and 1994 (Table 1). In 1986 the scaling exponents of F. mandshurica and L. olgensis were not significantly different from 2.0, and this means that these two species had almost no interaction with other tree species. In $1994 P$. amurense, $F$. mandshurica had little interspecific interaction. The interaction strength of $U$. pumila, P. koraiensis, $A$. mono, L. olgensis and all others increased significantly from 1986 to 1994, respectively. For the others, the interaction did not change significantly.

Table 1. The overall multispecies interaction strength of each tree species along NECT in 1986 and 1994

Tree species

\section{Betula}

platyphylla

Abies nephrolepis

Tilia spp.

Betula costata

Betula dahurica

Juglans

mandshurica

Phellodendron

amurense

Fraxinus

rhynchophylla

Populus

davidiana

Ulmus pumila

Quercus

mongolica

Pinus koraiensis

Acer mono

Fraxinus

mandshurica

Picea spp.

Larix olgensis

\section{Short Scaling exponent of names}

\section{Species competition coefficient}

Interspecies means crowding

\begin{tabular}{lllllll} 
& $\mathbf{1 9 8 6}$ & $\mathbf{1 9 9 4}$ & $\mathbf{1 9 8 6}$ & $\mathbf{1 9 9 4}$ & $\mathbf{1 9 8 6}$ & $\mathbf{1 9 9 4}$ \\
\cline { 2 - 7 } Bp & 0.7239 & 0.4533 & 2.1864 & 2.1281 & 1.9377 & 1.7717 \\
An & 0.5237 & 0.6916 & 3.0009 & 2.0257 & 3.1860 & 2.2442 \\
$\mathrm{~T}$ & 0.2983 & 0.2938 & 1.4917 & 1.5820 & 3.5350 & 1.4281 \\
$\mathrm{Bc}$ & 1.0219 & 1.1296 & 2.1548 & 2.3771 & 2.0132 & 2.2986 \\
$\mathrm{Bd}$ & 1.4591 & 0.9864 & 2.8569 & 7.6667 & 4.5567 & 11.7714 \\
$\mathrm{Jm}$ & 0.8538 & 2.2995 & 4.6809 & 2.5693 & 6.2414 & 2.5274 \\
& & & & & & \\
$\mathrm{~Pa}$ & 1.0534 & 1.6035 & 7.0397 & 5.9343 & 7.8765 & 14.8661 \\
& & & & & & \\
Fr & 0.8776 & 1.000 & 1.4701 & 3.1407 & 3.0405 & 3.1429 \\
& & & & & & \\
$\mathrm{Pd}$ & 1.3169 & 1.2939 & 3.8120 & 1.8553 & 5.3103 & 3.4112 \\
& & & & & & \\
$\mathrm{Up}$ & 3.0375 & 0.7301 & 3.2849 & 4.5130 & 3.1731 & 9.0832 \\
$\mathrm{Qm}$ & 1.5130 & 1.3048 & 0.4923 & 0.2815 & 0.3415 & 0.1920 \\
& & & & & & \\
$\mathrm{Pk}$ & 0.7130 & 0.3609 & 0.9070 & 4.2567 & 3.7867 & 4.1054 \\
Am & 0.2443 & -1.9976 & 2.1216 & 2.7808 & 3.8798 & 3.4514 \\
Fm & 2.4114 & 2.5841 & 1.1744 & 0.6941 & 1.3006 & 1.9525 \\
& & & & & & \\
$\mathrm{P}$ & 0.6649 & 0.8182 & 0.3827 & 2.2018 & 2.2394 & 1.8928 \\
Lo & 2.0385 & 1.0246 & 0.1756 & 0.2256 & 0.1848 & 0.2052
\end{tabular}

The interaction coefficients by the resource exploitation competition of $B$. dahurica, Tilia spp., F. rhynchophylla, U. pumila, P. koraiensis, A. mono and Picea spp. increased from 1986 to 1994 (Table 1), but it decreased for A. nephrolepis, J. mandshurica, $P$. amurense, $P$. davidiana, $Q$. mongolica and $F$. mandshurica. Only the interaction coefficients of $B$. platyphylla and L. olgensis changed slightly. 
The mean crowding coefficient increased for B. costata, B. dahurica, P. amurense, U. pumila, P. koraiensis and F. mandshurica (Table 1), and it decreased for A. nephrolepis, Tilia spp., J. mandshurica, P. davidiana, Q. mongolica, A. mono and Picea spp. But for B. platyphylla, F. rhynchophylla and L. olgensis it changed only slightly.

\section{Spatial change of interspecific interaction for B. dahurica and P. koraiensis}

For the sake of simplicity, here only the spatial change of multispecies interactions for B. dahurica and P. koraiensis at each $50 \mathrm{~km}$ was shown, respectively (Fig. 1). B. dahurica was chosen because its overall interaction with other species over the entire study area did not change significantly, but its spatial distribution of multispecies interactions changed from 1986 to 1994. P. koraiensis is an important species for industrial timber and a keystone species in the vegetation of this area. The scaling exponent of B. dahurica was 0 at $0-200 \mathrm{~km}$ in 1994 , there was a higher change of interspecific interaction at this area. The interaction strengths of the same species at different locations were different. For $P$. koraiensis the interaction strength changed at $0-50 \mathrm{~km}$ and $250-300 \mathrm{~km}$. The sudden change of multispecies interactions may provide information of disturbances and dramatic environmental change.
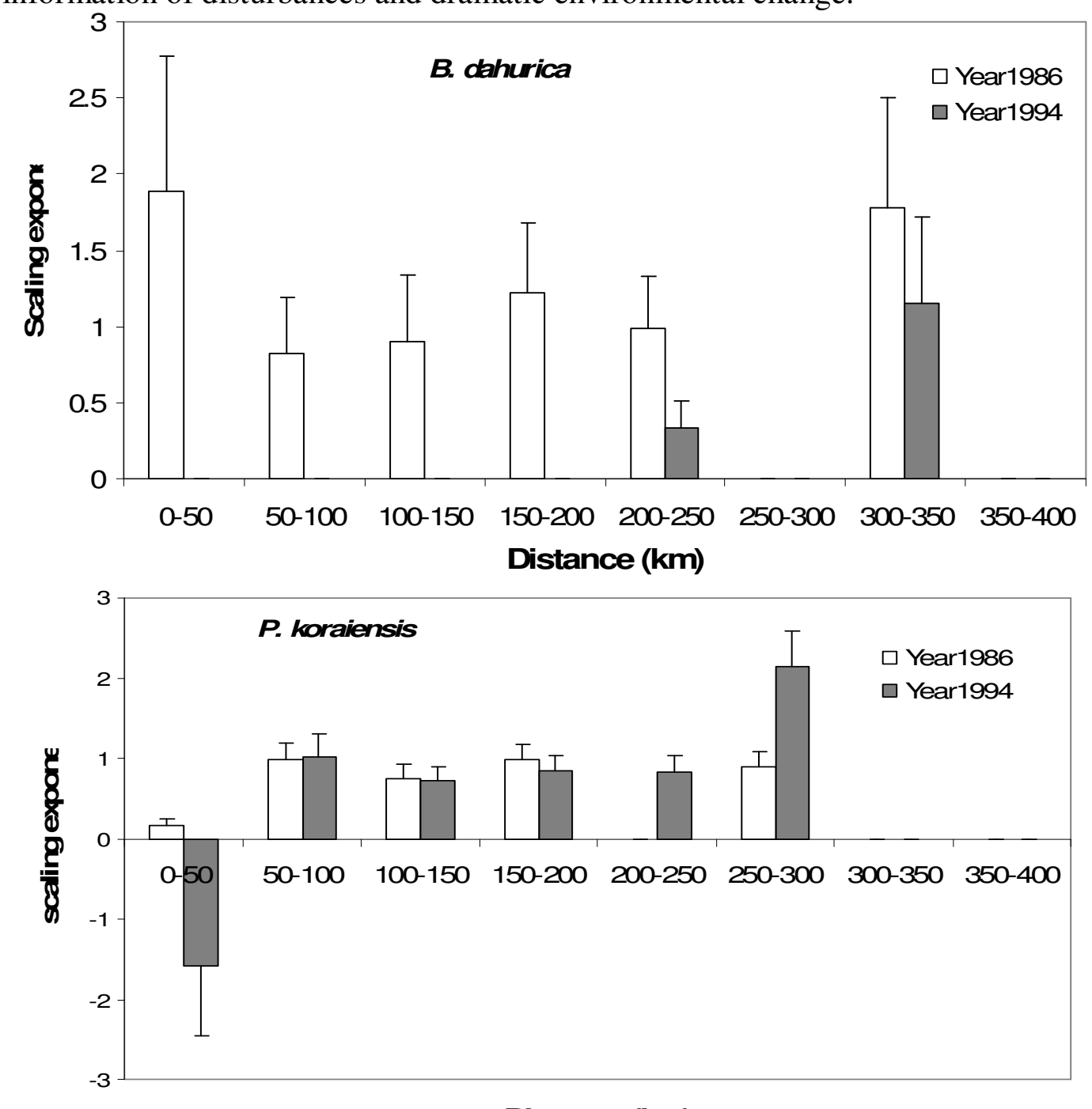

Distance (km)

Figure 1. The spatial distribution of multispecies interactions of B. dahurica and P. koraiensis at each $50 \mathrm{~km}$ along NECT by Taylor's power law. 
The spatial distribution of species interaction coefficients estimated by resource exploitation competition changed for both B. dahurica and P. koraiensis (Fig. 2). For B. dahurica the species interaction coefficients increased at $200-250 \mathrm{~km}$ and $300-350 \mathrm{~km}$. This is consistent with the result from scaling exponent. For P. koraiensis the interaction coefficients changed little at $0-50 \mathrm{~km}$, but it increased beyond $100 \mathrm{~km}$.
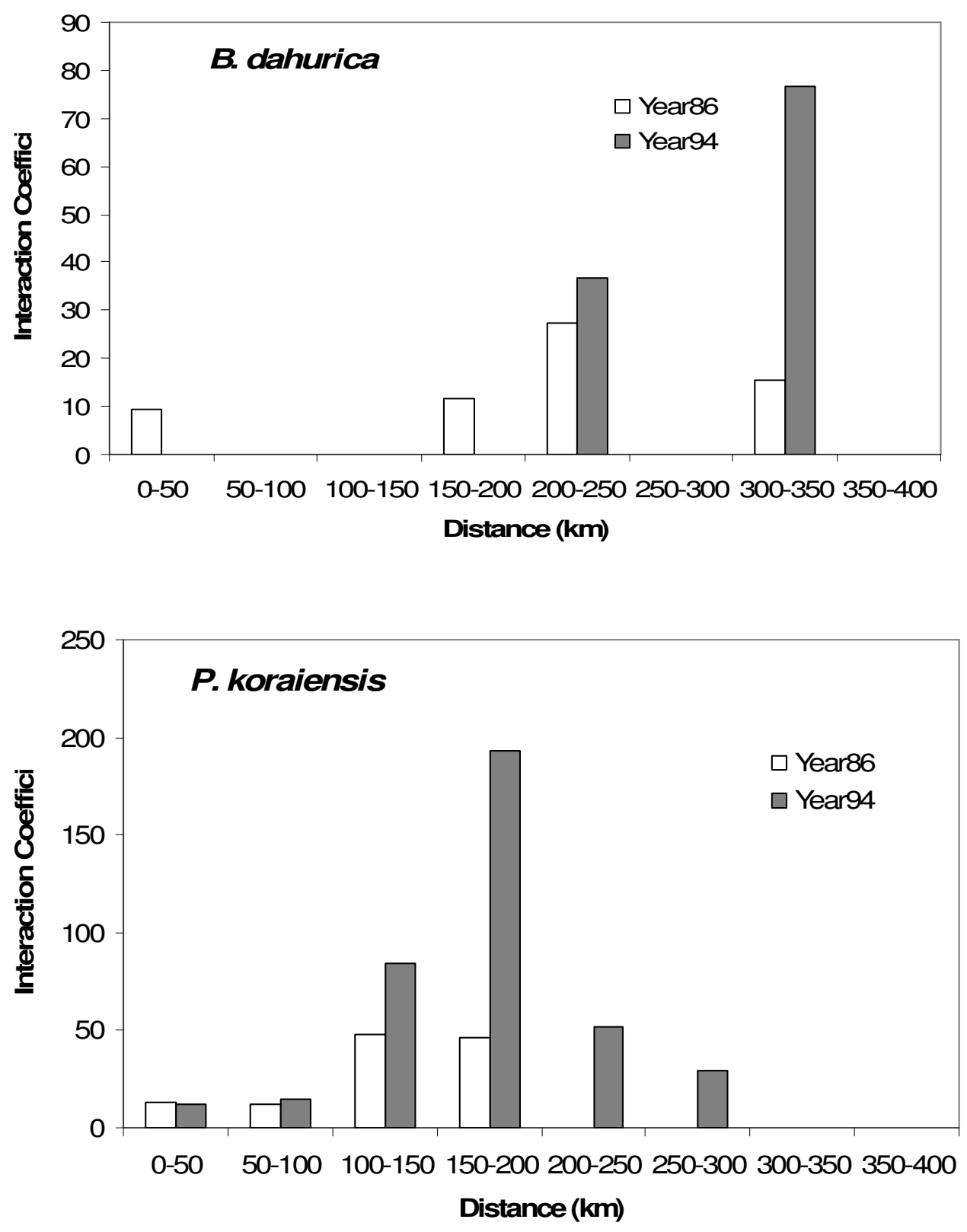

Figure 2. The spatial distribution of multispecies interactions of B. dahurica and P. koraiensis at each $50 \mathrm{~km}$ along NECT by species competition coefficient. 
For the spatial distribution of mean crowding coefficient of $B$. dahurica, the mean crowding coefficient decreased at 0-200 km and increased slightly at 300-350 km (Fig. $3)$. For $P$. koraiensis it decreased at $50-100 \mathrm{~km}$ and increased at $0-50$ and $150-300 \mathrm{~km}$. Most of these results are consistent with the other two methods.
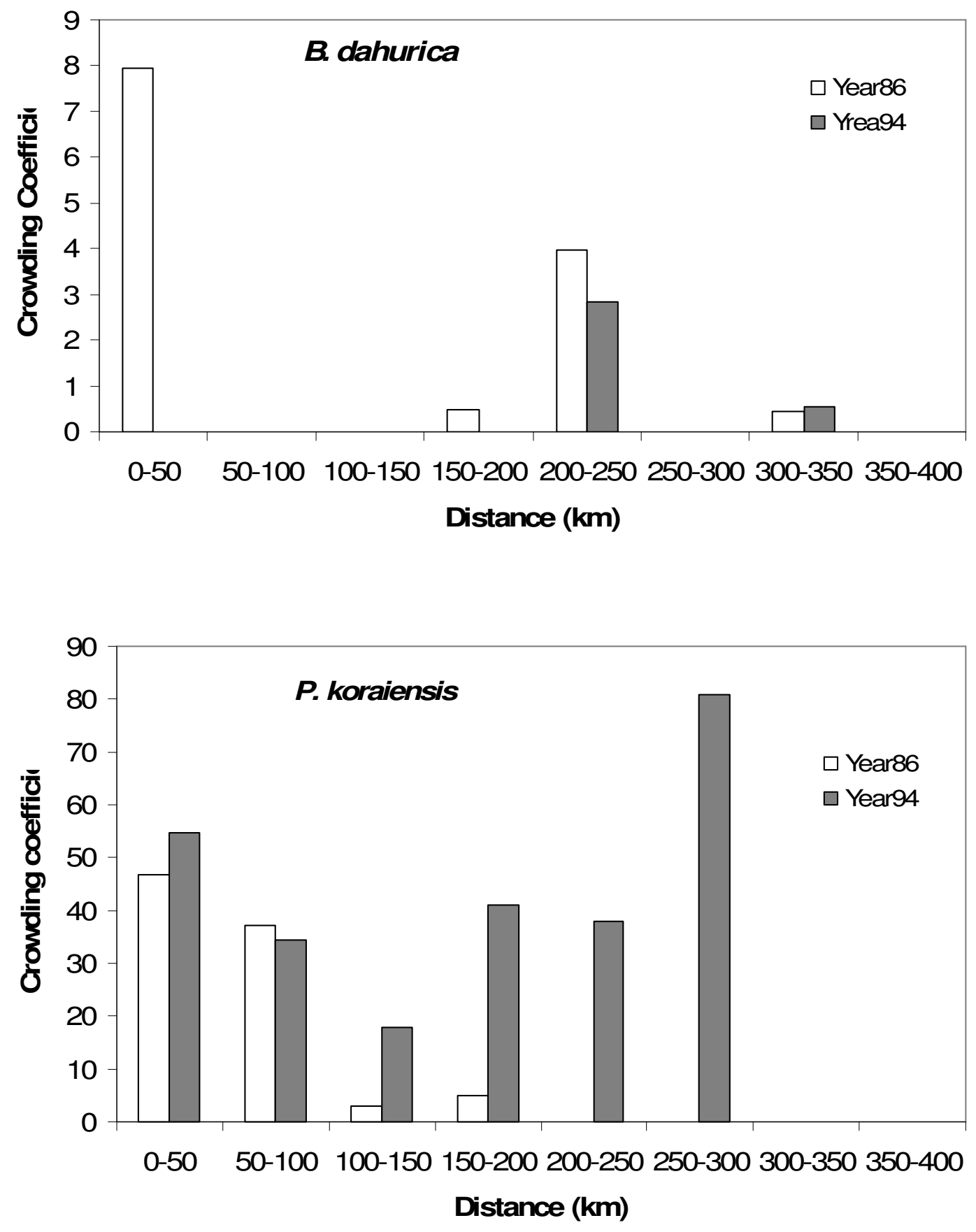

Figure 3. The spatial distribution of multispecies interaction of $B$. dahurica and $P$. koraiensis at each $50 \mathrm{~km}$ along NECT by mean crowding measurement. 


\section{Discussion}

There are differences and similarities between the estimates of species interaction using these three methods. The scaling exponent of Taylor's power law demonstrated that the multispecies interaction for $J$. mandshurica, $U$. pumila, $P$. koraiensis, A. mono and $L$. olgensis changed, while for most other species the interaction did not change significantly. As competitive interactions increase between species, the average scaling exponent decreases from 2 to 1 [17]. The possible explanations for the insensitivity of most species are the most abundant species often has a higher carrying capacity and/or is a superior competitor, it experiences weaker interspecific competition and has lower variability; but the variability in the rare species from other species' competition is relatively large, and this substantially increases the variance in the abundance of the rare species [17]. In this study, the relative percentages of abundance for each species in 1986 and 1994 are shown in Table 2. J. mandshurica, P. amurense, F. rhynchophylla, $P$. koraiensis and Picea spp. had a lower relative percentage of abundance, respectively; While L. olgensis, $U$. pumila and A. mono had a higher relative percentage of abundance, respectively. B. dahurica, $F$. rhynchophylla, $Q$. mongolica, Tillia spp. and A. nephrolepis had a higher change in the relative percentage of abundance in comparison with the others. However, by Taylor's power law it can be inferred that $J$. mandshurica, $P$. koraiensis, L. olgensis, U. pumila and A. mono could be described as species that experienced higher interaction because their scaling exponents changed significantly. The interaction strength was also changed for A. nephrolepis, B. costata, $P$. amurense, F. rhynchophylla, F. mandshurica, Picea spp., B. platyphylla, B. dahurica, but the change was not significant. The species with a higher change in the multispecies interaction estimated by Taylor's power law also had a change in the relative percentage of abundance (Table 2). But a species with a change in the relative abundance may not change its interaction with all other species because other species may also change their abundances during the same time period. Therefore, it is not enough to simply measure the abundance of each species over time in our current monitoring. Our results indicated that not all rare species experienced higher interaction from other species and environment. A. mono and Tilia spp., which were not rare species, also experienced a higher interaction from all others in 1986 and 1994. This result may be useful to identify the rare species that experienced high multispecies interaction or the species affecting the rare species. It has great implications for rare species preservation and management.

Using the species resource exploitation competition coefficients, it was found that all species had changed in multispecies interactions between 1986 and 1994 except $B$. platyphylla and $L$. olgensis. The interaction strength changed more for $B$. dahurica, $P$. koraiensis, J. mandshurica, P. davidiana, Picea spp. and F. rhynchophylla. Because this method is based on the species relative percentage of abundance, it assumes that species with a lower relative percentage of abundance experienced a relative higher multispecies interaction pressure. Some species which had changed the strength of multispecies interactions also changed their relative abundance, such as A. nephrolepis, $J$. mandshurica, but some did not. By using the interspecies mean crowding measurements, it was found that B. dahurica, J. mandshurica, P. amurense, Tilia spp., $P$. davidiana and $U$. pumila had higher degree of change in multispecies interaction coefficients. This result is similar with the result estimated by the species resource exploitation competition coefficients. Some species which had changed their 
multispecies interaction changed their relative abundance, such as A. nephrolepis, J. mandshurica, but some did not.

Table 2. Relative abundance of each species along NECT in 1986 and 1994

$$
\begin{array}{lll}
\text { Tree species } & \text { Short } & \text { Relative abundance (\%) } \\
\text { names } &
\end{array}
$$

\begin{tabular}{|c|c|c|c|}
\hline & & 1986 & 1994 \\
\hline Betula platyphylla & $\mathrm{Bp}$ & 3.0466 & 4.2061 \\
\hline Abies nephrolepis & An & 2.5538 & 4.2061 \\
\hline Tilia spp. & $\mathrm{T}$ & 12.4104 & 14.1341 \\
\hline Betula costata & $\mathrm{Bc}$ & 3.4498 & 4.4714 \\
\hline Betula dahurica & $\mathrm{Bd}$ & 4.3907 & 0.6063 \\
\hline $\begin{array}{l}\text { Juglans } \\
\text { mandshurica }\end{array}$ & $\mathrm{Jm}$ & 1.8817 & 2.2357 \\
\hline $\begin{array}{l}\text { Phellodendron } \\
\text { amurense }\end{array}$ & $\mathrm{Pa}$ & 2.1057 & 1.2884 \\
\hline $\begin{array}{l}\text { Fraxinus } \\
\text { rhynchophylla }\end{array}$ & Fr & 2.1505 & 0.5305 \\
\hline Populus davidiana & $\mathrm{Pd}$ & 3.2258 & 2.3873 \\
\hline Ulmus pumila & Up & 6.3620 & 5.8734 \\
\hline Quercus mongolica & Qm & 37.6792 & 35.7711 \\
\hline Pinus koraiensis & $\mathrm{Pk}$ & 2.6433 & 3.4104 \\
\hline Acer mono & $\mathrm{Am}$ & 6.3620 & 7.5028 \\
\hline $\begin{array}{l}\text { Fraxinus } \\
\text { mandshurica }\end{array}$ & $\mathrm{Fm}$ & 3.2706 & 2.8420 \\
\hline Picea spp. & $\mathrm{P}$ & 2.7330 & 3.8272 \\
\hline Larix olgensis & Lo & 5.7348 & 6.7071 \\
\hline
\end{tabular}

Because of the climate gradients and species adaptation to these gradients, the distribution of species and their functional group is also different along NECT [4, 6]. Species preferring moisture grow in the eastern part of the study area (moist end from beginning) (e.g., P. koraiensis); in contrast, species preferring dry conditions usually appear in the western part (dry end) (e.g., Q. mongolica). Here only two species were explained in details for their spatial distribution of interactions. The spatial distribution of multispecies interaction of $B$. dahurica and $P$. koraiensis changed in different areas from 1986 to 1994. With no interspecific competition in resources exploitation for $B$. dahurica at 0-200 km, its scaling exponent and crowding coefficient both became $0 . B$. dahurica may die out more easily because of (i) its shade-intolerance at early succession stages [3]; (ii) competition from other tree species [3]; (iii) drought and high air temperature [6]; and (iv) insects or pathogens [22]. At the distance of 200-250 km and $300-350 \mathrm{~km}$ the competition for resources increased, and the scaling exponent decreased; but its crowding coefficient decreased at 200-250 km and only increased slightly at 300-350 km. For $P$. koraiensis the competition coefficient in resource exploitation increased at 50-300 km, and its crowding coefficient also increased, but its scaling exponent became negative at 0-50 km and more than 2.0 at $250-300 \mathrm{~km}$, respectively. By analyzing the spatial change of scaling exponent, interspecific competition coefficient and crowding coefficient at different scales, we can monitor the interspecific interaction of tree species. However, the biological meaning of scaling exponent that is less than 0 and more than 2.0 is still not straightforward. Disturbances, such as wind damage and pathogens, frequently occur in this area just like any forests, 
but the main factor is precipitation change [6]. At some locations land use was changed during this time period, but it did not occur in the area of these permanent plots.

Serious drought can cause some trees to die or to be easily damaged by disturbances (e.g., wind). Disturbances can change the species interaction by changing interspecies competitions and environmental conditions. These measurements reflected changes in species viability and also year-to-year variability. Sometimes year-to-year variability is very important for species viability. The way to analyze this kind of variability is to use the combination of three methods and use long term data. Therefore, the combination of three measurements can reflect the change in species viability at different areas along NECT.

The different results from each of the three methods may be primarily due to the fact that the scaling exponent of Taylor's power law considered interactions both from species and environment; whereas, the species resource exploitation competition coefficients and the interspecies mean crowding did not consider both. The species resource exploitation competition coefficient considers only competition for resources and is a measure of exploitation competition under the assumption of no inference [10]. The interspecies mean crowding indicates the extent of crowding [14]. The relative percentage of abundance is mainly considered in the species resource exploitation competition coefficient, and real abundance is considered by mean crowding methods. L. olgensis received more competition from other species using the scaling exponent of Taylor's power law, but it was considered little competition and no significant change by the species resource exploitation competition coefficients and mean crowding methods. The species resource exploitation competition coefficients and mean crowding methods both determined that $P$. davidina and $Q$. mongolica decreased interactions with others, but the method of scaling exponent of Taylor's power law did not (Table 3).

Table 3. Comparison of the results from the three methods $(*$ indicates that this species is also detected by at least another method)

Method

Taylor's power law

\section{Decreased interaction strength}

J. mandshurica*, $A$. nephrolepis*, B. costata, $P$. amurense*, F. rhynchophylla, $F$. mandshurica*, Picea spp.*

\section{A. nephrolepis*, J.}

Species competition coefficient mandshurica*, $P$. amurense $*, P$.

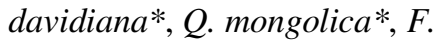
mandshurica*

A. nephrolepis*, Tilia spp., $J$.

Mean crowding
Increased interaction strength

U. pumila*, P. koraiensis*, A.

mono*, L. olgensis, $B$.

platyphylla, B. dahurica*

B. dahurica*, Tilia spp., $F$. rhynchophylla, $U$. pumila*, $P$. koraiensis*, A. mono*, Picea spp.

B. costata, B. dahurica*, $P$. amurense, $U$. pumila*, $P$.

koraiensis*, F. mandshurica

Therefore, the three methods describe the different perspectives of species interactions, but also have relationships with each other. The increased interactions between multiple species may result in change in relative percentage of abundance or may not, but with a relative lower percentage of abundance, such as with rare species, 
extinction may occur in this area. By combining the results of three methods, it may be helpful to monitor species viability under the interactions with other species and environment and provide management strategies for species monitoring and conservation. The species with increased interactions by the three methods need higher priority to monitor and manage, such as $U$. pumila, P. koraiensis and A. mono. If species with increased interactions were determined by the scaling exponent of Taylor's power law, but were not detected by the other methods, then, the species may experience more pressure from environment. Species without increased interactions determined by one of the methods, but were detected to have increased interactions by the other two methods, may be at medium priority to manage, such as L. olgensis and $B$. dahurica. Species without detected interactions by any of the three methods may be at low priorities to manage. The combination of these three methods may be useful for monitoring the spatial and temporal dynamics of species under multispecies interaction if combined with environmental information, and provide some practices for conservation (e.g., control the abundance of certain species with higher interspecific interaction). But the biological meaning of a scaling exponent less than 0 and more than 2.0 is still not clear, and its relationships with resource competition and mean crowding require further study. Due to the data limitation we can not test our results here. More research remains to be done to test whether this method can be applied to other ecosystems or systems with more than one trophic level, such as animal-plant interaction.

Acknowledgements. This work was partially supported by the School of Agricultural and Environmental Sciences of Alabama A \& M University. Special thanks to Prof. X.-S. Zhang from Chinese Academy of Sciences for providing the data set, W. Stone, B.-L. Li, C. Barrows and A. Jenks for suggestions and editorial assistance.

\section{REFERENCES}

[1] Anderson, R.M., Gordon, D.M., Crawley, M.J., Hassell, M.P. (1982): Variability in the abundance of animal and plant species. - Nature 296: 245-248.

[2] Akcakaya, H.R. (2000): Conservation and management for multiple species: integrating field research and modeling into management decisions. - Environmental Management 26(Sup. 1): 75-83.

[3] Chen, X. \& Li, B.-L. (2003): Effect of global climate change and human disturbances on tree diversity of the forest regenerating from clear-cuts of mixed broadleaved Korean pine forest in Northeast China. -Chemosphere 51: 215-226.

[4] Chen, X. \& Li, B.-L. (2005): Spatial variability of plant functional types of trees along Northeast China Transect. —Applied Ecology and Environmental Research 3: 39-49.

[5] Chen, X., Li, B.-L. \& Collins, S.L. (2005): Multiscale monitoring of a multispecies case study: two grass species at Sevilleta. - Plant Ecology 179: 149-154.

[6] Chen, X., Zhou, G. \& Zhang, X.-S. (2002): Spatial characteristics and change for tree species along the North East China Transect (NECT). -Plant Ecology 164: 65-74.

[7] Chesson, P. (2000): Mechanisms of maintenance of species diversity. - Annual Review of Ecology and Systematics 31: 343-366.

[8] Culver, D.C. (1970): Analysis of simple cave communities: niche separation of species packing. -Ecology 54: 102-110.

[9] Davidson, D.W. (1980): Some consequences of diffuse competition in a desert ant community. -American Naturalist 116: 92-105.

[10] Emlen, J.M. (1984): Population Biology. MacMilian Publishing Company, New York. 
[11] Hurlbert, S.H. (1978): The measurement of niche overlap and some relatives. - Ecology 59: 67-77.

[12] Hilderbrand, R.H. (2003): The roles of carrying capacity, immigration, and population synchrony on persistence of stream-resident cutthroat trout. - Biological Conservation 110:257-266.

[13] IGBP. (1995): Spatial extrapolation and modeling on IGBP transects. -Global Change Report 36:15-20.

[14] Iwao, S. (1977): Analysis of spatial association between two species based on the interspecies mean crowding. - Research in Population Ecology 18:243-260.

[15] Iwao, S. (1979) The $M^{*}-M$ method for analyzing the distribution patterns of single and mixed species populations. -In: Patil, G.P. \& Rosenzweig, M.L. (eds): Contemporary Quantitative Ecology and Related Ecometrics. International Co-operative Publishing House, Fairland, Maryland, pp. 215-228.

[16] Kendal, W.S. (2002): Spatial aggregation of the Colorado potato beetle described by an exponential dispersion model. -Ecological Modelling 151:245-260.

[17] Kilpatrick, A.M. \& Ives, A.R. (2003): Species interactions can explain Taylor's power law for ecological time series. - Nature 422: 65-68.

[18] Law, R., Herben, T. \& Dieckmann, U. (1997): Non-manipulative estimates of competition coefficients in a montane grassland community. - Journal of Ecology 85: 505-517.

[19] Levins, R. (1968): Evolution in Changing Environments. Princeton University Press, Princeton, NJ.

[20] Lloyd, M. (1967): Mean crowding. — Journal of Animal Ecology 36:1-30.

[21] Loew, B. (2000): Multiple species habitat conservation planning: goals and strategies of local governments. —Environmental Management 26(Sup. 1): 15-21.

[22] Meng, F., Shao, L., Huang, Y., Song, R., Xue, Y., Xu, G. \& Guo, L. (1991): Decomposition microfungus flora in the litter of natural secondary poplar and birch stands. - In: Zhou, X. (ed): Long-Term Located Research on Forest Ecosystems. Northeast Forestry University Press, Harbin, P.R. China, pp. 281-286.

[23] Root, K.V., Akcakaya, R. \& Ginzburg, L. (2003): A multispecies approach to ecological valuation and conservation. -Conservation Biology 17:196-206.

[24] Scott, T.A. \& Sullivan, J.E. (2000): The selection and design of multiple-species habitat preserves. -Environmental Management 26(Sup. 1): 37-53.

[25] Stenseth, N.C., Chan, K-S., Tong, H., Boonstra, R., Boutin, S., Krebs, C.J., Post, E., O’Donoghue, M., Yoccoz, N.G., Forchhammer, M.C. \& Hurrell, J.W. (1999): Common dynamic structure of Canada lynx populations within three climate regions. - Science 285:1071-1073.

[26] Sokal, R.R. \& Rohlf, F.J. (1995): Biometry. Third edition. W.H. Freeman and Company, New York, pp. 541-554.

[27] Taylor, L.R., Woiwod, I.P. \& Perry, J.N. (1978): The density-dependence of spatial behavior and the rarity of randomness. - Journal of Animal Ecology 47: 383-406.

[28] Taylor, L.R. \& Woiwod, I.P. (1980): Temporal stability as a density-dependent species characteristic. -Journal of Animal Ecology 49: 209-224.

[29] Yeaton, R.I. (1974): An ecological analysis of chaparral and pine forest bird communities on Santa Cruz Island and mainland California. -Ecology 55: 959-973. 